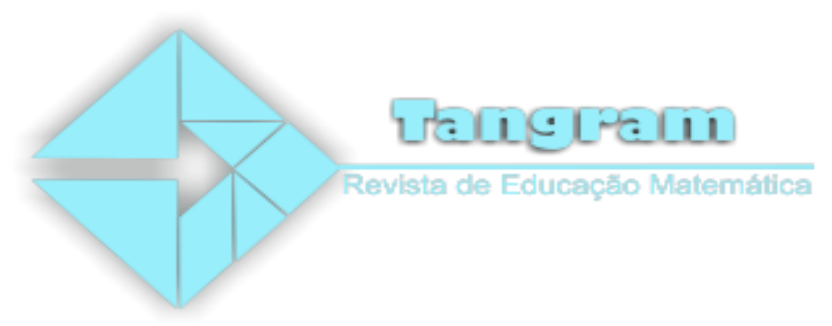

\title{
Apresentação: As diferentes perspectivas da Educação Financeira
}

Esta edição continua promovendo a reflexão sobre os estudos que evidenciem a Educação Financeira e como esta é benéfica para a área de Educação Matemática e Educação em geral. Os artigos permitem observarmos algumas possibilidades de atividades para uso em sala de aula.

Assim, temos 6 artigos brasileiros das regiões de São Paulo, Ceará, Rio Grande do Sul, Pernambuco e Paraná e 1 artigo estrangeiro de Honduras.

$\mathrm{O}$ primeiro artigo intitulado $\mathrm{O}$ uso de histórias em quadrinhos para o ensino de Educação Financeira no ciclo de alfabetização, escrito pelos pesquisadores Nilton José Neves Cordeiro, Madeline Gurgel Barreto Maia, Carina Brunehilde Pinto Silva, realizam um estudo documental que identifica histórias em quadrinhos para a Educação Financeira. Os autores mostram três propostas de histórias em quadrinhos da Turma da Monica.

A segunda investigação Análise de Itens sobre Sistema Monetário Brasileiro na Provinha Brasil de Matemática à Luz da Teoria dos Campos Conceituais, redigida pelos autores Ivana Siqueira Caldeira, Vinicius Carvalho Beck, João Alberto da Silva,nos trzem reflexões sobre como os problemas do sistema monetários estão relacionados com a Teoria dos Campos Conceituais de Vergnaud.

A terceira pesquisa Economia doméstica e Educação financeira na escola: diferenças a partir do Gênero das educadoras matemáticas Luzia de Fatima Barbosa Fernandes e Denise Vilela, mostram um recorte da pesquisa documental, que possui como foco analisar a economia doméstica na escola básica. As autoras analisaram diversos documentos da educação brasileira, com suporte teórico sociológico. Com as análises realizadas observou-se as mudanças de tratamento nos assuntos financeiros e no contexto escolar, identificando distinções de conteúdo de acordo com o gênero ( educação para meninas e educação para meninos.

O artigo Una exploración de interés, ahorro e inversión estudiando una muestra poblacional de Honduras investigou um grupo de estudantes da educação primária , da

Tangram - Revista de Educação Matemática, Dourados - MS - v.2 n1. , pp. 01 - 02 (2018) 
universidade e professores de Honduras identificando quais são os conhecimentos que estes possuem sobre a Educação Financeira .

O quinto artigo Educação financeira nos livros didáticos de Matemática do Ensino Médio escrito por David Pires Dias e Artur Alberti Gaban, demonstram uma investigação de como a Educação Financeira apresenta-se nos livros didáticos do Ensino Médio. Utiliza como suporte teórico os referenciais da Educação Matemática Crítica.

O sexto artigo foi escrito por Stephany Karoline de Souza Chiappetta e José Roberto Silva e intitula-se como Uma proposta para o ensino de Educação Financeira embasada na Etnomatemática: Consumo Consciente a partir do contexto do Orçamento Financeiro. Os autores apresentam um estudo dissertativo sobre o uso da Etnomatemática em uma turma de jovens e adultos de Pernambuco e demonstram como a Educação Financeira esta presente nos conhecimentos prévios deste segmento educacional.

O último artigo desta edição é A Matemática Financeira e Educação Financeira: impactos na formação inicial do professor, escrito por Adriana Stefanello Somavilla, Evandro Carlos Andretti e Tania Stella Bassoi. Os autores apresentam reflexões sobre a formação inicial dos professores e da possível utilização da Educação Financeira no processos formativos.

Com isso,desejamos uma boa leitura à todos que se interessam pela temática .

Editores

Edvonete Souza de Alencar

Tiago Dziekaniak Figueiredo

Aldrin Cleyde da Cunha

Adriana Fátima de Souza Miola

Tangram - Revista de Educação Matemática, Dourados - MS - v2 n. 1, pp. 01 - 02 (2018) 